\title{
Organisation of the coding exons and mutational screening of the uncoupling protein 3 gene in subjects with juvenile-onset obesity
}

\author{
S. A. Urhammer ${ }^{1}$, L. T. Dalgaard ${ }^{1}$, T. I. A. Sørensen ${ }^{2,3}$, A. Tybjærg-Hansen ${ }^{2,5}$, S. M. Echwald ${ }^{1}$, T. Andersen ${ }^{2,4}$, \\ J. O. Clausen ${ }^{6}$ O. Pedersen ${ }^{1}$ \\ ${ }^{1}$ Steno Diabetes Center and Hagedorn Research Institute, Copenhagen, Denmark \\ ${ }^{2}$ Copenhagen City Heart Study, National University Hospital, Copenhagen, Denmark \\ ${ }^{3}$ Danish Epidemiology Science Centre at the Institute of Preventive Medicine, Copenhagen University Hospital, Denmark \\ ${ }^{4}$ Roskilde County Hospital, Denmark \\ ${ }^{5}$ Department of Clinical Biochemistry, Herlev University Hospital, Copenhagen, Denmark \\ ${ }^{6}$ Center of Preventive Medicine, Glostrup University Hospital, Copenhagen, Denmark
}

\begin{abstract}
Summary Uncoupling proteins (UCPs) are mitochondrial transporters that uncouple the cellular respiration releasing stored energy as heat. Recently a third member of the UCP family was identified. Human UCP3 is different from UCP1 and UCP2 by its high and preferential expression in skeletal muscle and consequently the UCP3 gene is an attractive candidate gene for obesity. In this study we have determined the intron/exon organization of the coding region of the UCP3 gene and performed single strand conformation polymorphism (SSCP) analysis and direct sequencing of variants of the gene in 60 Caucasian subjects with juvenile-onset obesity. We detected 4 nucleotide substitutions in the intron regions and 2 silent amino acid variants. During the identification of the intron/exon structure of the
\end{abstract}

gene in a normal healthy male subject with a BMI of $23.5 \mathrm{~kg} / \mathrm{m}^{2}$, a nucleotide substitution replacing a glycine with a serine was identified at codon 84 . This variant was neither found among 156 subjects with juvenile-onset obesity nor among 205 control subjects. In a population based sample of 380 young healthy subjects the Gly/Ser84 variant was found in one female subject with a BMI of $25.5 \mathrm{~kg} / \mathrm{m}^{2}$ and a fat mass of $23.7 \mathrm{~kg}$. We conclude it is unlikely that variants in the coding region of the UCP3 gene contribute to the pathogenesis of juvenile-onset obesity among Danish Caucasians. [Diabetologia (1998) 41: 241-244]

Keywords uncoupling protein 3, obesity, genetics, mutation.
Obesity is a multifactorial disorder with a strong genetic component. Studies in twins [1] and in adoptees [2] indicate that most familial aggregation of obesity is attributable to genetic influence rather than to shared family environment. The search for obesity candidate genes has focused on those that have a role in energy metabolism. Uncoupling proteins are mitochondrial transporters that dissipate the electrochemical gradient generated in the electron transfer chain within the mitochondria and thereby uncouple

Received: 8 October 1997

and in revised form: 30 October 1997

Corresponding author: S. A. Urhammer, M. D., Steno Diabetes Center, Niels Steensens Vej 2, DK-2820 Gentofte, Copenhagen, Denmark

Abbreviations: UCP1-3, Uncoupling protein 1-3; SSCP, single strand conformation polymorphism. the cellular respiration leading to heat production instead of energy storage. Whereas UCP1 is expressed uniquely in brown adipose tissue and thereby may be of less importance in adult humans, UCP2 has a wide tissue distribution and may play a role in energy balance. Mutational analysis of the coding region of the UCP2 gene has, however, not revealed any genetic variability contributing to the development of obesity in Danish Caucasians [3]. Very recently a third member of the UCP family was reported $[4,5]$. At the amino acid level this protein is $57 \%$ identical to UCP1 and $71 \%$ identical to UCP2. It is different from UCP1 and UCP2 by its high and preferential expression in skeletal muscle in humans. Since skeletal muscle is a major contributer to whole body thermogenesis in adult humans, UCP3 may be an important mediator of nonshivering thermogenesis and the UCP3 gene is thus a logical candidate gene for obesity. The objectives of the present study were 1) to de- 
Table 1. Nucleotide sequences of DNA primers used for PCR amplification of the UCP3 gene

\begin{tabular}{|c|c|c|c|}
\hline intron & sense primer $\left(5^{\prime} \rightarrow 3^{\prime}\right)$ & antisense primer $\left(5^{\prime} \rightarrow 3^{\prime}\right)$ & $\mathrm{T}_{\text {annealing }} / \mathrm{C}_{\mathrm{MgCl} 2}$ \\
\hline 1 & agg agg ggc cat cca atc & gga ggc acg tct gaa gg & $60^{\circ} \mathrm{C} / 2,0 \mathrm{mmol} / 1$ \\
\hline 2 & aaa ggg act ggg cag agc & ccc att gta ggg get gc & $60^{\circ} \mathrm{C} / 1,5 \mathrm{mmol} / 1$ \\
\hline 3 & tac cgt ggc gtg ctg gg & gta tgc tgg cet gaa atc & $65^{\circ} \mathrm{C} / 1,5 \mathrm{mmol} / \mathrm{l}$ \\
\hline 5 & tga gga atg cta tcg tca ac & gcc tgg agg tga gtt $c$ & $60^{\circ} \mathrm{C} / 1,5 \mathrm{mmol} / 1$ \\
\hline 6 & ctt ctg tgc cac agt ggt g & act ggt ttc gga cac gtt ag & $60^{\circ} \mathrm{C} / 1,0 \mathrm{mmol} / 1$ \\
\hline \multicolumn{4}{|l|}{ exon } \\
\hline 3 & tgt aaa acg acg gcc agt tgt gca $\operatorname{cgc}$ agc ccc ttc & cag gaa aca gct atg acc cta gac ttc cet ggt ctc ttg ac & $55^{\circ} \mathrm{C} / 2,0 \mathrm{mmol} / \mathrm{l}$ \\
\hline 4 & tgt aaa acg acg gcc agt gca gcc ccg cag aga ac & cag gaa aca gct atg acc acg cca tgc tgg gag tcc & $55^{\circ} \mathrm{C} / 2,5 \mathrm{mmol} / \mathrm{l}$ \\
\hline 5 & tgt aaa acg acg gcc agt cca ttt ctc cca ttt ccc & cag gaa aca gct atg acc gcc cac tcc acg gag ttc & $55^{\circ} \mathrm{C} / 2,0 \mathrm{mmol} / 1$ \\
\hline 6 & tgt aaa acg acg gcc agt gag ttg ggg aca aac agt gc & cag gaa aca gct atg acc acg gta gcc aca ttc gaa ag & $60^{\circ} \mathrm{C} / 2,0 \mathrm{mmol} / 1$ \\
\hline 7 & tgt aaa acg acg gcc agt ggg aga gca cac gca tc & cag gaa aca gct atg acc act ggt ttc gga cac gtt ag & $60^{\circ} \mathrm{C} / 2,0 \mathrm{mmol} / 1$ \\
\hline
\end{tabular}

$\mathrm{T}_{\text {annealing }}$ and $\mathrm{C}_{\mathrm{MgCl} 2}$ denote the annealing temperature and the $\mathrm{MgCl}_{2}$ concentration, respectively, used for PCR amplification. ${ }^{a}$ Non-translated region, ${ }^{\mathrm{b}}$ Translated region. Exons and

termine the intron/exon organization of the coding region of the UCP3 gene, 2) to analyse for variations in the coding region of the gene in subjects with juvenile-onset obesity and 3) to evaluate whether identified variants were associated with juvenile-onset obesity in Caucasian subjects or related to estimates of obesity and impaired insulin sensitivity in a cohort of young healthy Danes.

\section{Subjects and methods}

Cohort used in the primary mutational scanning. The primary mutational analysis and the subsequent association studies of variants of the UCP3 gene were performed in study groups selected from a population of young Caucasian men of Danish ancestry, who at the age of 18-26 years were examined at the draft board, and who, in addition, had attended school in the municipality of Copenhagen, where height and weight had been measured as part of the school health examinations [6]. The population was further restricted to those who were examined at the Copenhagen City Heart Study Program in 1981-1983 [7] and again in 1992-1994. The cohort of men with juvenile onset obesity included 156 subjects who had a BMI of $31.0 \mathrm{~kg} / \mathrm{m}^{2}$ or more at the draft board examination. From this obese cohort 60 subjects were randomly selected for the initial mutational screening.

Cohort used in the case-control study. As a control cohort 250 draftees were selected at random as every hundredth from the same population [6]. Weight and height at different ages were recorded.

Genomic DNA was obtained from blood samples, drawn at the last examination at the Copenhagen City Heart Study.

Cohort used in the genotype-phenotype interaction study. A cohort of 380 subjects randomly recruited from a population of young healthy individuals aged 18-32 years, who in 1979-1980 and again in 1984-1985 as children had participated in an epidemiological blood pressure survey [8] in a specified part of Copenhagen were genotyped for the Gly/Ser84 mutation of UCP3. All were Danish Caucasians by self-identification. $\mathrm{BMI}$, waist-to-hip ratio and and fat mass, were analysed as pre- introns are numbered with respect to the non-translated exon upstream of the first coding exon viously described [8]. The insulin sensitivity index was estimated from an intravenous glucose tolerance test in combination with injection of intravenous tolbutamide as previously described [8]. Physiological and anthropometric characteristics of this population sample have been reported [8].

Prior to participation informed consent was obtained from all subjects. The study was approved by the ethical committee of Copenhagen and was in accordance with the principles of the Declaration of Helsinki II.

Identification of the intron/exon organisation of the coding part of the UCP3 gene. Genomic DNA was obtained from human leukocyte nuclei using standard methods. In order to amplify the putative introns of UCP3 primer pairs (Table 1) were designed from the partial UCP3 cDNA sequence (Genbank accession number: AF001787) according to the intron/exon organisation of UCP1. Introns were PCR amplified using $300 \mathrm{ng}$ of genomic DNA, 2 units of TaqPlus (Stratagene, La Jolla, Calif., USA), $0.2 \mu \mathrm{mol} / \mathrm{l}$ of each primer and $\mathrm{MgCl}_{2}$ as described (Table 1). PCR conditions were denaturation at $94^{\circ} \mathrm{C}$ for $3 \mathrm{~min}$ followed by 35 cycles of denaturation for $30 \mathrm{~s}$, annealing at Tanneal (Table 1) for $30 \mathrm{~s}$ and extension at $72^{\circ} \mathrm{C}$ for $4 \mathrm{~min}$, with a final extension at $72^{\circ} \mathrm{C}$ for $9 \mathrm{~min}$. Cycles were performed on a GeneAmp 9600 Thermocycler (Perkin-Elmer/Cetus, Norwalk, Conn., USA). The total PCR product was subsequently run on a $1 \%$ agarose gel and putative intron bands were excised and purified using Microcon 50 spin columns with agarose filters inserted. Direct sequencing was performed using ABI PRISM dRhodamine Dye Terminator Cycle Sequencing Kit and ABI PRISM 377 automatic DNA sequencer (Perkin Elmer, Foster City, Calif., USA).

Identification of mutations in the UCP3 gene. SSCP analysis was performed on the entire coding region, including intronexon boundaries and the non-translated region of the first coding exon of the UCP3 gene. PCR amplification of the 6 exons (7 segments) was carried out in a volume of $25 \mu \mathrm{l}$, containing $100 \mathrm{ng}$ of genomic DNA prepared from peripheral blood leukocytes, $0.2 \mu \mathrm{mol} / 1$ of each primer, 0.313 units of Taq DNA polymerase (Perkin-Elmer/Cetus, Norwalk, Conn., USA), $\mathrm{MgCl}_{2}$ as stated (Table 1) and including $0.125 \mu \mathrm{l}$ of a $37-\mathrm{MBq} /$ $\mathrm{ml}$ solution $\left(\alpha{ }^{32} \mathrm{P}\right) \mathrm{dCTP}$ (Amersham, Buckinghamshire, UK). Primers (Table 1) were designed from the partial intron sequencing described above. The reverse primer used for am- 


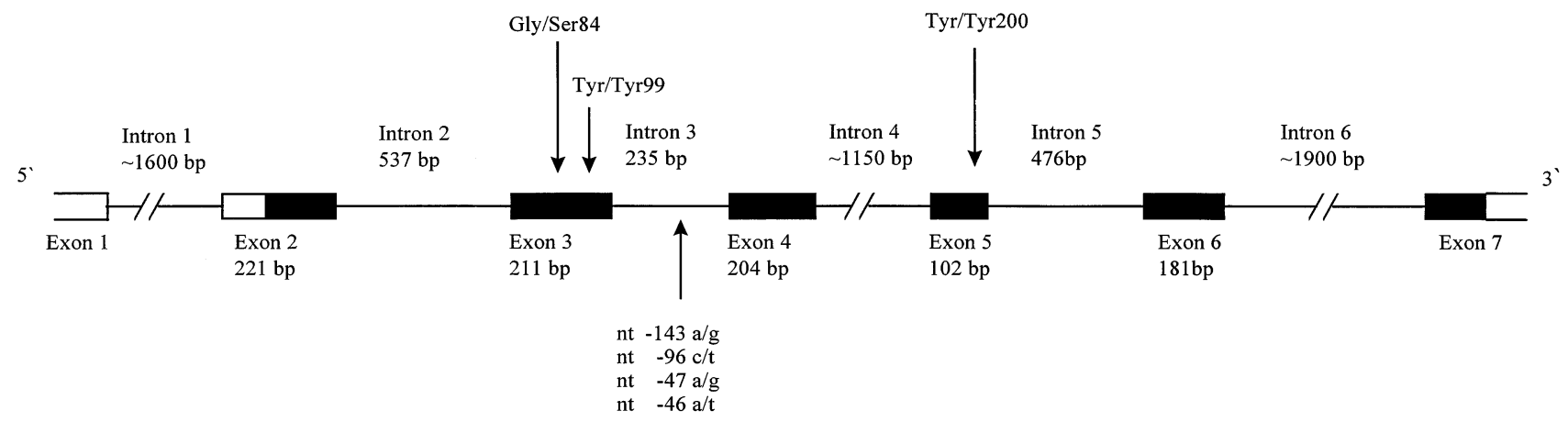

Fig. 1. Intron-exon structure of the coding region of the human UCP3 gene. Lines and boxes indicate introns and exons, respectively. Exons and introns are numbered with respect to the exon upstream of the first coding exon. The coding regions are indicated by filled boxes whereas the non-translated sequences are depicted by open boxes. The sizes of the segments are indicated. The nucleotide positions of intron variants are indicated with respect to the splice acceptor site. The codon number of the mutations identified in exons are shown

plification of the last coding exon was designed from the 3'UTR sequence. PCR conditions were denaturation at $94^{\circ} \mathrm{C}$ for 3 min followed by 35 cycles of denaturation for $30 \mathrm{~s}$, annealing at T-anneal (Table 1) for $30 \mathrm{~s}$ and extension at $72^{\circ} \mathrm{C}$ for $30 \mathrm{~s}$, with a final extension at $72^{\circ} \mathrm{C}$ for $9 \mathrm{~min}$. PCR products were mixed with loading buffer, denatured and allowed to partially re-anneal in order to generate heteroduplices and were finally analysed by non-denaturing gel electrophoresis at two different conditions as previously described [9]. In our laboratory these conditions provide a sensitivity of the SSCP of more than $90 \%$ which is consistent with estimates from other groups [10]. Segments showing variation in migration were reamplified by PCR, purified using Microcon 100 microconcentrators and sequenced directly using ABI PRISM Dye Primer Cycle Sequencing Kit with Amplitaq DNA Polymerase FS and ABI prism 377 (Perkin Elmer, Foster City, Calif., USA). All nucleotide variants were identified on both strands.

Screening for the Gly/Ser84 amino acid mutation in the UCP3 gene. The DNA segment containing codon 84 was amplified as described above, including primers used for amplification of the second coding exon (Table 1). Restriction fragment length polymorphisms were detected after digestion overnight with 2 units of MspI. Fragments were resolved on a $3 \%$ agarose gel and visualised by staining with ethidium bromide.

\section{Results}

Analysis of the human UCP3 gene demonstrated that the gene is comprised of at least 7 exons of which 6 exons are coding (Fig.1). Exons are numbered with respect to the exon upstream of the first coding exon. All coding exons, the 3' region of exon 1 , which is non-translated and the 5' region of exon 7 , including some of the non-translated region and the entire intron 2, 3 and 5 were sequenced. In addition intron 1,4 and 6 were sequenced approxi- mately $100 \mathrm{bp}$ from the splice sites. The sequences surrounding splice junctions were in accordance with consensus sequences for RNA splicing. The sequence of the exons and adjacent introns have been deposited in the Genbank database (accession numbers: AFO26955-58).

SSCP-heteroduplex scanning and sequencing of migration variants of the UCP3 gene in 60 subjects with juvenile-onset obesity showed 6 nucleotide substitutions, 2 of which were located in exons and 4 in introns. In the third intron 4 variants were detected: $46 \mathrm{bp}$ upstream of exon 4 an $\mathrm{a} \rightarrow \mathrm{t}$ substitution was identified, $47 \mathrm{bp}$ and $143 \mathrm{bp}$ upstream, respectively, an $\mathrm{a} \rightarrow \mathrm{g}$ substitution was identified and $96 \mathrm{bp}$ upstream a c $\rightarrow \mathrm{t}$ substitution was found. In exon 3 at codon 99 and in exon 5 at codon 200 two silent variant were identified, $\operatorname{Tyr}($ tat $) \rightarrow \operatorname{Tyr}(\operatorname{tac})$ and $\operatorname{Tyr}(\operatorname{tac})$ $\rightarrow \operatorname{Tyr}($ tat $)$, respectively. At codon 84 a g $\rightarrow$ a substitution resulting in a Gly $(\mathrm{ggc}) \rightarrow \operatorname{Ser}(\mathrm{agc})$ replacement was detected during the determination of the intron/ exon structure of the gene in a normal, healthy male subject, with a BMI of $23.5 \mathrm{~kg} / \mathrm{m}^{2}$ and a waist-to-hip ratio of 0.93 . This amino acid variant was neither found among 156 subjects with juvenile-onset obesity nor among 205 control subjects. In the cohort of 380 young healthy subjects the Gly/Ser84 variant was identified in one female subject with a BMI of $25.5 \mathrm{~kg} / \mathrm{m}^{2}$, a fat mass of $23.7 \mathrm{~kg}$, a waist-to-hip ratio of 0.82 and an insulin sensitivity index of $15.2 \times 10^{-5}(\operatorname{minx} \mathrm{pmol} / \mathrm{l})^{-1}$. Values in the total cohort were (mean (SD)): 23.6 $(3.7) \mathrm{kg} / \mathrm{m}^{2}, 17.1(7.8) \mathrm{kg}, 0.82(0.07)$ and $15.2 \times 10^{-5}$ $\left(9.3 \times 10^{-5}\right)(\operatorname{minx} \mathrm{pmol} / \mathrm{l})^{-1}$, respectively.

\section{Discussion}

The recently cloned human UCP3 gene is an obvious candidate for a mediator of regulated thermogenesis in skeletal muscle. With the purpose of performing mutational analysis on genomic DNA we have in the present study delineated the intron/exon structure of the coding region of the gene. However, since the UCP3 mRNA transcript is predicted to be equal to or greater than $2.2 \mathrm{~kb}$ [5] and since the transcriptional start of the gene has not yet been reported, the UCP3 gene may comprise more than the identified 7 exons. 
The mutational analysis of the UCP3 gene demonstrated several nucleotide variants. None of the identified intron nucleotide substitutions or the two silent exon variants are located in the vicinity of splice junctions. It is therefore unlikely that the variants affect the splicing of the exons. We detected one exon variant changing an amino acid. This Gly/Ser84 replacement is a conservative amino acid change and when extrapolated from the structure of UCP1, which at the amino acid level is $57 \%$ homologous to UCP3, the Gly/Ser84 substitution is not predicted to be located within any functional domains of the gene. Moreover, as judging from the BMI, fat mass and waist-to-hip ratio of the two carriers of the variant our results indicate that this amino acid substitution in its heterozygous form has no major impact on the pathogenesis of obesity. Yet, it should be noted that the glycine at codon 84 is conserved in human UCP1, 2 and 3, respectively and the residue is located within one of the putative transmembrane regions of the gene. Structure-function studies at the cellular level are therefore needed to exclude a potential minor biological influence of the gene variant.

Despite a high sensitivity of the SSCP screening method used in this study, we failed to detect any frequent amino acid variants with potential impact on the function of the UCP3 protein. However, this does not exclude a role for the UCP3 gene in contributing to obesity in subsets of patients with specific forms of obesity. Furthermore, localisation and mutational screening of the regulatory regions and studies of the expression of the UCP3 gene in obese subjects are necessary in order to exclude the UCP3 gene as a risk factor for altered energy metabolism. In summary, genetic variation in the coding region of the human UCP3 gene is not involved in the pathogenesis of juvenileonset obesity in Danish Caucasian subjects.

Acknowledgements. The study was supported by grants from the University of Copenhagen, the Velux Foundation, the Danish Diabetes Association, the Danish Medical Research Council and EEC (BMH4-CT-950662). The authors thank Sandra Urioste, Annemette Forman, Lene Aabo, Helle Fjord- vang, Bente Mottlau, Susanne Kjellberg, Lis Ølholm and Marja Lis Halkjær for dedicated and careful technical assistance and Grete Lademann for secretarial support.

\section{References}

1. Stunkard AJ, Harris JR, Pedersen NL, McClearn GE (1990) The body mass index of twins who have been reared apart. N Eng J Med 322: 1483-1487

2. Sørensen TIA, Price RA, Stunkard AJ, Schulsinger F (1989) Genetics of obesity in adults adoptees and their biological siblings. BMJ 298: 87-90

3. Urhammer SA, Dalgaard LT, Sørensen TIA et al. (1997) Mutational analysis of the coding region of the uncoupling protein 2 gene in obese NIDDM patients: impact of a common amino acid polymorphism on juvenile and maturity onset forms of obesity and insulin resistance. Diabetologia 40: $1227-1230$

4. Boss O, Samec S, Paoloni-Giacobino A et al. (1997) Uncoupling protein-3: a new member of the mitochondrial carrier family with tissue-specific expression. FEBS Lett 408: 39-42

5. Vidal-Puig A, Solanes G, Grujic D, Flier JS, Lowell BB (1997) UCP3: an uncoupling protein homologue expressed preferentially and abundantly in skeletal Muscle and brown adipose tissue. Biochem Biophys Res Commun 235: 79-82

6. Sørensen TIA, Sonne-Holm S (1988) Risk in childhood of development of severe adult obesity: restrospective, population-based case-cohort study. Am J Epidemiol 14: 319326

7. Sonne-Holm S, Sørensen TIA, Jensen G, Schnohr P (1989) Long-term changes in body weight in adult obese and nonobese men. Int J Obesity 14: 319-326

8. Clausen JO, Borch-Johnsen K, Ibsen H et al. (1996) Insulin sensitivity index, acute insulin response, and glucose effectiveness in a population-based sample of 380 young healthy Caucasians. Analysis of the impact of gender, body fat, physical fitness, and life style factors. J Clin Invest 98: 1195-1209

9. Echwald SM, Bjørbæk C, Hansen Tet al. (1995) Identification of four amino acid substitutions in hexokinase II and studies of relationships to NIDDM, glucose effectiveness and insulin sensitivity. Diabetes 44: 347-353

10. Hayashi K (1992) PCR-SSCP: a method for detection of mutations. GATA 9: 73-79 